University of Nebraska - Lincoln

DigitalCommons@University of Nebraska - Lincoln

Nutrition and Health Sciences -- Faculty

Publications

Nutrition and Health Sciences, Department of

2018

\title{
Effects of intensity on muscle-specific voluntary electromechanical delay and relaxation electromechanical delay
}

\author{
Cory M. Smith \\ University of Nebraska - Lincoln, cmsmith7@utep.edu \\ Terry J. Housh \\ University of Nebraska-Lincoln, thoush1@unl.edu \\ Ethan C. Hill \\ University of Nebraska-Lincoln, ethan.hill@unl.edu \\ Josh L. Keller \\ University of Nebraska - Lincoln, jkeller@unl.edu \\ Glen O. Johnson \\ University of Nebraska - Lincoln
}

See next page for additional authors

Follow this and additional works at: https://digitalcommons.unl.edu/nutritionfacpub

Part of the Human and Clinical Nutrition Commons, Molecular, Genetic, and Biochemical Nutrition Commons, and the Other Nutrition Commons

Smith, Cory M.; Housh, Terry J.; Hill, Ethan C.; Keller, Josh L.; Johnson, Glen O.; and Schmidt, Richard J., "Effects of intensity on muscle-specific voluntary electromechanical delay and relaxation electromechanical delay" (2018). Nutrition and Health Sciences -- Faculty Publications. 151.

https://digitalcommons.unl.edu/nutritionfacpub/151

This Article is brought to you for free and open access by the Nutrition and Health Sciences, Department of at DigitalCommons@University of Nebraska - Lincoln. It has been accepted for inclusion in Nutrition and Health Sciences -- Faculty Publications by an authorized administrator of DigitalCommons@University of Nebraska Lincoln. 


\section{Authors}

Cory M. Smith, Terry J. Housh, Ethan C. Hill, Josh L. Keller, Glen O. Johnson, and Richard J. Schmidt 


\section{Effects of intensity on muscle-specific voluntary electromechanical delay and relaxation electromechanical delay}

Cory M. Smith, Terry J. Housh, Ethan C. Hill, Josh L. Keller, Glen O. Johnson \& Richard J. Schmidt

To cite this article: Cory M. Smith, Terry J. Housh, Ethan C. Hill, Josh L. Keller, Glen O. Johnson \& Richard J. Schmidt (2018) Effects of intensity on muscle-specific voluntary electromechanical delay and relaxation electromechanical delay, Journal of Sports Sciences, 36:11, 1196-1203, DOI: 10.1080/02640414.2017.1364403

To link to this article: https://doi.org/10.1080/02640414.2017.1364403

Published online: 09 Aug 2017.

Submit your article to this journal $\sqsubset$

Џ Article views: 160

View Crossmark data ¿ 


\title{
Effects of intensity on muscle-specific voluntary electromechanical delay and relaxation electromechanical delay
}

\author{
Cory M. Smith, Terry J. Housh, Ethan C. Hill, Josh L. Keller, Glen O. Johnson and Richard J. Schmidt \\ Department of Nutrition and Health Sciences, University of Nebraska - Lincoln, Lincoln, NE, USA
}

\begin{abstract}
The purposes of this study were to examine: 1) the potential muscle-specific differences in voluntary electromechanical delay (EMD) and relaxation electromechanical delay (R-EMD), and 2) the effects of intensity on EMD and R-EMD during step incremental isometric muscle actions from 10 to $100 \%$ maximal voluntary isometric contraction (MVIC). EMD and R-EMD measures were calculated from the simultaneous assessments of electromyography, mechanomyography, and force production from the vastus lateralis (VL), vastus medialis (VM), and rectus femoris (RF) during step isometric muscle actions. There were no differences between the $\mathrm{VL}, \mathrm{VM}$, and $\mathrm{RF}$ for the voluntary $E M D_{\mathrm{E}-\mathrm{M}}$ (onsets of the electromyographic to mechanomyographic signals), $E M D_{M-F}$ (onsets the mechanomyographic to force production), or $E M D_{E-F}$ (onsets of the electromyographic signal to force production) as well as R-EMD $D_{E-M}$ (cessation of electromyographic to mechanomyographic signal), R-EMD $\mathrm{M}_{-\mathrm{F}}$ (cessation of mechanomyographic signal to force cessation), or $\mathrm{R}_{-\mathrm{EMD}_{\mathrm{E}-\mathrm{F}}}$ (cessation of electromyorgraphic signal to force cessation) at any intensity. There were decreases in all EMD and R-EMD measures with increases in intensity. The relative contributions from $E M D_{E-M}$ and $E M D_{M-F}$ to $E M D_{E-F}$ as well as $R-E M D_{E-M}$ and $R-E M D_{M-F}$ to $\mathrm{R}-\mathrm{EMD}_{\mathrm{E}-\mathrm{F}}$ remained similar across all intensities. The superficial muscles of the quadriceps femoris shared similar EMD and R-EMD measurements.
\end{abstract}

ARTICLE HISTORY

Accepted 26 July 2017

KEYWORDS

EMD; R-EMD;

electromyography; mechanomyography; excitation-contraction coupling

\section{Introduction}

Electromechanical delay (EMD) is the time delay between the onset of electrical activation of the muscle and the onset of force production (Norman \& Komi, 1979). Typically, EMD has been operationally defined as the time period between the onset of the electromyographic (EMG) signal and the onset of force production during a muscle contraction. More recently, however, mechanomyography (MMG) has been used to identify the onset of the lateral oscillations associated with the contraction of skeletal muscle and provides additional information regarding the factors that contribute to EMD (Emiliano Cè, Rampichini, \& Esposito, 2015; Orizio et al., 1997). Specifically, the EMG signal identifies when an electrical impulse activates the muscle and the MMG signal reflects the initiation of movement from the activated muscle fibers (Basmajian \& De Luca, 1985). The time difference between the onsets of the EMG and MMG signals is a measure of the total duration of the events from the motor unit action potentials travelling along the sarcolemma to cross-bridge formation (excitation-contraction coupling) (Orizio et al., 1997). The onset of the MMG signal to the onset of force production is a measure of the time required to take up the muscle-tendon unit slack before force transmission can occur, which has been termed the series elastic component (Orizio et al., 1997). Thus, simultaneous assessments of EMG, MMG, and force production allows for the identification of the onset of the EMG signal to the onset of the MMG signal $\left(E M D_{E-M}\right)$, the onset of the MMG signal to the onset of force production $\left(E M D_{M-F}\right)$, and the onset of the EMG signal to the onset of force production $\left(E M D_{E-F}\right)$ (Emiliano Cè et al., 2015; Orizio et al., 1997). Therefore, $\mathrm{EMD}_{\mathrm{E}-\mathrm{M}}$ and $\mathrm{EMD}_{\mathrm{M}-\mathrm{F}}$ can measure the relative contributions from excitation-contraction coupling and the series elastic component, respectively, to the overall time duration of $E M D_{E-F}$.

Relaxation electromechanical delay (R-EMD) is the time delay between the cessation of the electrical activation of the muscle and the cessation of force production (Ferris-Hood, Threlkeld, Horn, \& Shapiro, 1995). Thus, R-EMD represents the electrochemical processes associated with the reversal of excitation-contraction coupling and the mechanical events related to the relaxation of the series elastic component returning to a resting state after a contraction (Ferris-Hood et al., 1995). The simultaneous assessment of the EMG, MMG, and force signals allow for the identification of the cessation of the EMG signal to the cessation of the $M M G$ signal $\left(R-E M D_{E-M}\right)$, cessation of the MMG signal to cessation of force production $\left(R-E M D_{M-F}\right)$, and the cessation of the EMG signal to the cessation of force production $\left(\mathrm{R}-E M D_{E-F}\right)$ (Emiliano Cè et al., 2015). The electrochemical processes which are reflected by $R-E M D_{E-M}$ during the relaxation phase of a muscle action represent the reversal of excitation-contraction coupling and include: 1 ) the cessation of motor unit action potentials, 2) $\mathrm{Ca}^{2+}$ reuptake by the sarcoplasmic reticulum and blocking of actin/myosin binding by troponin and tropomyosin, and 3) cross-bridges switching from a force generating to a non-force generating state (Emiliano Cè 
et al., 2013; Ferris-Hood et al., 1995). The mechanical events following muscle relaxation are reflected by $R-E M D_{M-F}$ which represent the reversal of the series elastic component including: 1) returning of sarcomeres towards resting lengths, and 2) releasing of the series elastic component to a relaxed state (Emiliano Cè et al., 2013; Ferris-Hood et al., 1995). Thus, examining the relative contributions from $R-E M D_{E-M}$ and $R-E M D_{M-F}$ to $R-E M D_{E-F}$ allows for the identification of the relative contributions of the reversal of excitation-contraction coupling $\left(R-E M D_{E-M}\right)$ and relaxation of the series elastic component $\left(R-E M D_{M-F}\right)$ to the total R-EMD $D_{E-F}$. It is important to note, however, a previous study (Emiliano Cè et al., 2015) has suggested that using noninvasive measurements, such as EMG and MMG, may not precisely measure when electromechanical mechanisms cease and mechanical events occur during the relaxation phase. Therefore, when referring to the electrochemical and mechanical processes of R-EMD caution should be taken in that electrochemical and mechanical processes are likely occurring simultaneously at some time-points. The current method proposed, however, provided the closest approximation of the change points from electrochemical and mechanical processes currently capable using non-invasive measures.

Previous studies (Emiliano Cè et al., 2015; Cè, Rampichini, Limonta, \& Esposito, 2014; Emiliano Cè et al., 2015; Esposito, Orizio, \& Veicsteinas, 1998; Rampichini, Cè, Limonta, \& Esposito, 2014) have examined either $\mathrm{EMD}_{\mathrm{E}-\mathrm{F}}$ or $\mathrm{R}-\mathrm{EMD}_{\mathrm{E}-\mathrm{F}}$ using the simultaneous assessments of EMG, MMG, and force signals to identify the relative contributions from excitation-contraction coupling and the series elastic component to the total $E M D_{E-F}$ and $R-E M D_{E-F}$ during maximal muscle action. Few studies, however, have examined the EMD or R-EMD measures at various submaximal intensities. For example, Emiliano Cè et al. (2013) reported decreases in $E M D_{E-M}$. $E M D_{M-F}$, and $E M D_{E-F}$ with increases in intensity from the biceps brachii at 20,40,60,80, and 100\% MVIC, however, no study have simultaneously collected EMD and R-EMD measures. Many clinical, sporting, and occupational activities are performed at submaximal intensities and, therefore, it would be valuable to examine the potential differences in the mechanisms responsible for the contraction and relaxation of a muscle and muscle-group. In addition, to our knowledge no previous studies have examined EMD and R-EMD using a combined EMG, MMG, and force simultaneously from the 3 superficial muscles of the quadriceps. Therefore, the purposes of the present study were to examine: 1) potential muscle-specific differences in voluntary $E M D_{E-F}, E M D_{E-M}$, $E M D_{M-F}$ as well as R-EMD $D_{E-F}, R-E M D_{E-M}$, and R-EMD $D_{M-F}$ from the vastus lateralis (VL), vastus medialis (VM), and rectus femoris (RF); 2) the effects of intensity on voluntary $E M D_{E-F}, E M D_{E-M}, E M D_{M-F}$ as well as voluntary $R-E M D_{E-F}, R-E M D_{E-M}$, and $R-E M D_{M-F}$; and 3) the relative contributions from $E M D_{E-M}$ and $E M D_{M-F}$ to $E M D_{E-F}$ as well as $R-E M D_{E-M}$ and $R-E M D_{M-F}$ to $R-E M D_{E-F}$.

\section{Material and methods}

\section{Subjects}

Ten men (mean \pm SD age $23.1 \pm 3.2 \mathrm{yr}$; body mass $79.1 \pm 6.9 \mathrm{~kg}$; height $178.2 \pm 5.8 \mathrm{~cm}$ ) volunteered to participate in this study. The subjects ranged between 20 to 27 years of age and were free from any musculoskeletal injuries or neuromuscular disorders, and performed resistance training for at least 6 months prior to the study. This study was approved by the University of Nebraska - Lincoln Institutional Review Board, and all subjects signed a written informed consent and completed a health history questionnaire prior to participation. In addition, this study was aligned with the Declaration of Helsinki.

\section{Isometric step muscle actions}

Subjects performed a warm-up consisting of 5 to 8 submaximal isometric contractions at approximately $50-80 \%$ of their perceived maximal voluntary isometric contraction (MVIC) force. Then each subject performed 2, 6-s MVIC muscle actions with 2-min of rest after each trial. Afterwards, subjects performed a series of randomly ordered submaximal isometric step muscle actions at $10,20,30,40,50,60,70,80$, and $90 \%$ MVIC which were determined from the highest MVIC torque value of the 2 trials. Each isometric step muscle action was held for approximately 4-s with a digital display of their force production on a screen placed in front of the subjects. A minimum of 1-min of rest was given between each step isometric muscle action to avoid any effects of fatigue. All isometric muscle actions were performed at a knee joint angle of $120^{\circ}$ ( $180^{\circ}$ being full extension) for optimal force production (Kulig, Andrews, \& Hay, 1984). Isometric muscle actions were chosen to limit any potential effect of dynamic movements on the EMG, MMG, EMD, or R-EMD values that may exist

\section{Electromyography, mechanomyographic, and force signal}

Bipolar electrode arrangements $(\mathrm{Ag} / \mathrm{AgCl}$, AccuSensor, Lynn Medical, Wixom, MI, USA) were placed on the VL, VM, and RF of the dominant leg (based on kicking preference) with an interelectrode distance of $30 \mathrm{~mm}$. The skin was dry shaven, abraded, and cleaned with isopropyl alcohol prior to placing the electrodes. For the $\mathrm{VL}$, the bipolar electrode arrangements were placed $66 \%$ the distance between the anterior superior iliac spine (ASIS) and the lateral border of the patella and orientated at a $20^{\circ}$ angle to approximate the pennation angle of the muscle fibers (Abe, Kumagai, \& Brechue, 2000; Hermens et al., 1999). For the VM, the bipolar electrode arrangements were placed $80 \%$ the distance between the ASIS and the joint space in front of the anterior border of the medial ligament and orientated at a $53^{\circ}$ angle to approximate the pennation angle of the muscle fibers (Hermens et al., 1999; Smith et al., 2016). For the RF, the bipolar electrode arrangements were placed $50 \%$ the distance between the ASIS and the superior border of the patella (Hermens et al., 1999). A reference electrode was placed over the ASIS. The MMG signals were measured using accelerometers (EGAS-FT10/V05, Measurement Specialties, Inc., Hampton, VA) placed between the bipolar electrode arrangements on the $V L, V M$, and RF using double-sided adhesive foam tape. The EMG and MMG signals were zero-meaned and bandpass filtered (fourthorder Butterworth) at $10-500 \mathrm{~Hz}$ and $5-100 \mathrm{~Hz}$, respectively. Force production was measured using a custom-fitted load cell (Omegadyne, model LC402, range 0-500 lbs, Stamford, CT) attached to the shin pad of the leg extension machine 
(LifeFitness, Rosemont, IL). All signals were collected at a sampling rate of 2000 per second and were processed using custom programs written with LabVIEW programming software (Version 15.0, National Instruments, Austin TX).

\section{Electromechanical delay}

The voluntary EMD measurements were determined from the onset of the EMG signal to the onset of the MMG signal $\left(E M D_{E-M}\right)$ onset of the MMG signal to the onset of force production (EMD $_{M-}$ $\mathrm{F}$ ), and the onset of the EMG signal to the onset of force production $\left(E M D_{E-F}\right)$ (Figure 1). The onset of EMG, MMG, and force were determined by the condition of three standard deviations (SDs) from the mean baseline noise observed for each signal (Begovic, Zhou, Li, Wang, \& Zheng, 2014; Costa et al., 2012; Stock, Olinghouse, Mota, Drusch, \& Thompson, 2015) The mean of each EMD measurements were then calculated (Figure 1).

\section{Relaxation electromechanical delay}

The R-EMD measurements were determined as the time periods from the cessation of the EMG signal to the cessation of the $M M G$ signal $\left(R-E M D_{E-M}\right)$, cessation of the $M M G$ signal to force returning to baseline $\left(R-E M D_{M-F}\right)$, and the cessation of the EMG signal to force returning to baseline $\left(R-E M D_{E-F}\right)$. The cessation of the EMG and MMG signals as well as when force return to baseline were determined by the condition of three SD's from the mean baseline noise observed for each signal after the MVIC (Begovic et al., 2014; Costa et al., 2012; Stock et al., 2015). The mean of each R-EMD measurements were then calculated. All EMD and R-EMD measurements were selected off-line by the primary investigator using a custom written LabVIEW program that provided interactive graphical viewing of each signal (Figure 1)

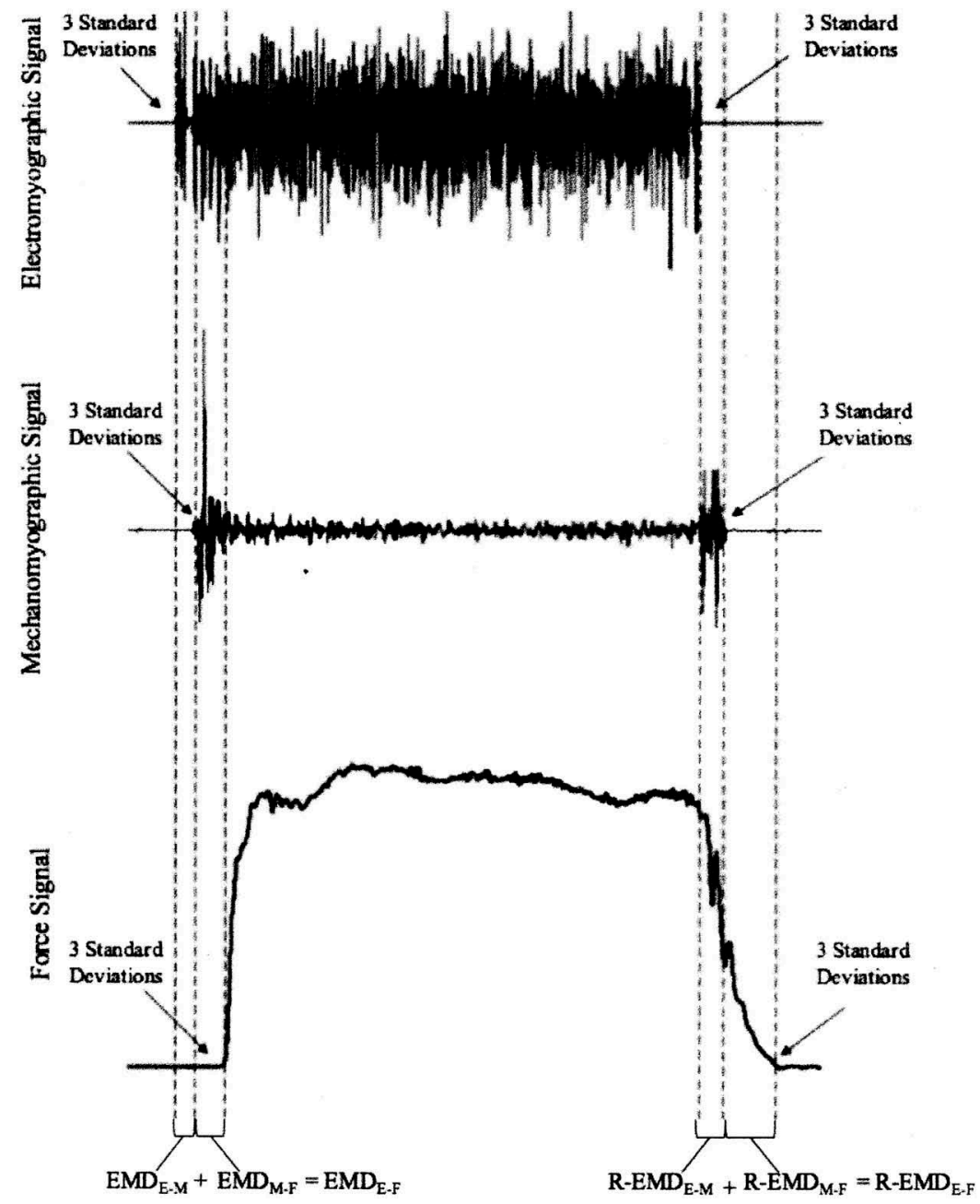

Figure 1. Graphical representation of the electromyographic, mechanomyograpic, and force combination for the determinations of electromechanical delay (EMD) and relaxation electromechanical delay (R-EMD) measures from Subject 12. Together, these signals allowed for the identification of the onset of the electromyographic signal to the onset of the mechanomyographic signal (EMDE-M), onset of the mechanomyographic signal to the onset of force production (EMDM-F), and onset of the electromyographic signal to the onset of force production (EMDE-F) as well as the cessation of the electromyographic signal to the cessation of the mechanomyographic signal (R-EMDE-M), cessation of the mechanomyographic signal to the cessation of force production (R-EMDM-F), and the cessation of the electromyographic signal to the cessation of force production (R-EMDE-F). 


\section{Statistical analyses}

\section{Electromechanical delay}

A 3 (Muscle: VL, VM, and RF) x 3 (EMD: $E_{\mathrm{E}-\mathrm{F}}, \mathrm{EMD}_{\mathrm{M}-\mathrm{F}}$, and $\mathrm{EMD}_{\mathrm{E}-\mathrm{F}}$ ) x 10 (Intensity: 10, 20, 30,40,50,60,70,80 90, and 100\% MVIC) repeated measures ANOVA was performed. Follow-up two- and one-way repeated measures ANOVAs and paired sampled $t$-tests were performed when appropriate.

\section{Relaxation electromechanical delay}

A 3 (Muscle: VL, VM, and RF) x 3 (R-EMD: R-EMD ${ }_{E-F}, R-E M D_{M-F}$, and $R-E M D_{E-F}$ ) $x 10$ (Intensity: 10, 20, 30,40,50,60,70,80 90, and $100 \% \mathrm{MVIC}$ ) repeated measures ANOVA was performed. Follow-up two- and one-way repeated measures ANOVAs with Tukey post-hoc tests were performed when appropriate. An alpha of $p \leq 0.05$ was considered statistically significant for all statistical analyses (SPSS Version 22.0, Armonk, NY).

\section{Results}

\section{Electromechanical delay}

The 3 (Muscle: VL, VM, and RF) x 3 (EMD: EMD ${ }_{E-F}, E_{M-F}$, and $\mathrm{EMD}_{\mathrm{E}-\mathrm{F}}$ ) $\mathrm{x} 10$ (Intensity: 10, 20, 30,40,50,60,70,80 90, and 100\% $\mathrm{MVIC}$ ) repeated measures ANOVA indicated no significant 3way interaction ( $p=0.42, \eta_{p}^{2}=0.10$ ) or 2-way interactions for Muscle x EMD ( $\left.p=0.57, \eta_{\mathrm{p}}^{2}=0.06\right)$ or Muscle $\times$ Intensity $\left(p=0.36, \eta_{p}^{2}=0.11\right)$. There was, however, a significant 2-way interaction for EMD x Intensity $\left(p<0.01, \eta_{p}^{2}=0.44\right)$. A follow-up 2-way (EMD x Intensity) repeated measures ANOVA (collapsed across muscle) indicated a significant $\left(p<0.01, \eta_{p}^{2}=0.99\right)$ interaction. Post-hoc comparisons were performed comparing $E M D_{E-M}$ to $E M D_{M-F}$ for each intensity $(10,20,30,40,50,60,70$, 80,90 , and $100 \% \mathrm{MVIC}$ ) (Figure 2). EMD $\mathrm{E}_{\mathrm{F}}$ was not compared to $E M D_{E-M}$ and $E M D_{M-F}$ because it is the sum of the two variables and, therefore, is always greater than either individual values (Keppel, 1991). These post-hoc analyses indicated that $\mathrm{EMD}_{\mathrm{E}-\mathrm{M}}$ was significantly $(p<0.01)$ less than $\mathrm{EMD}_{\mathrm{M}-\mathrm{F}}$ for all intensities $(10,20,30,40,50,60,70,80,90$, and 100\% MVIC) (Figure 2). In addition, Figure 3 shows the results of the significant one-way ( $1 \times 10)$ repeated measures ANOVAs with Tukey post-hoc tests for $\mathrm{EMD}_{\mathrm{E}-\mathrm{M}} \mathrm{x}$ Intensity $\left(p<0.01 ; \eta_{\mathrm{p}}^{2}=0.55\right), \mathrm{EMD}_{\mathrm{M}-\mathrm{F}} \mathrm{x}$ Intensity $\left(p<0.01 ; \eta_{\mathrm{p}}^{2}=0.89\right)$, and $\mathrm{EMD}_{\mathrm{E}-\mathrm{F}} \mathrm{x}$ Intensity $\left(p<0.01 ; \eta_{\mathrm{p}}^{2}=0.97\right)$.

\section{Relaxation electromechanical delay}

The 3 (Muscle: VL, VM, and RF) x 3 (R-EMD: R-EMD $D_{E-F}, R-E M D_{M-F}$ and $\mathrm{R}-\mathrm{EMD}_{\mathrm{E}-\mathrm{F}}$ ) $\mathrm{x} 10$ (Intensity: 10, 20, 30,40,50,60,70,80 90, and $100 \% \mathrm{MVIC}$ ) repeated measures ANOVA indicated no significant 3-way interaction ( $p=0.64, \eta_{\mathrm{p}}^{2}=0.09$ ) or 2-way interactions for Muscle x R-EMD ( $\left.p=0.55, \eta_{\mathrm{p}}^{2}=0.08\right)$ or Muscle $\mathrm{x}$ Intensity $\left(p=0.18, \eta_{p}^{2}=0.13\right)$. There was, however, a significant 2-way interaction for R-EMD x Intensity ( $p<0.01, \eta_{\mathrm{p}}^{2}=0.37$ ). A follow-up 2-way (R-EMD x Intensity) repeated measures ANOVA (collapsed across muscle) indicated a significant $\left(p<0.01, \eta_{\mathrm{p}}^{2}=0.67\right)$ interaction. Post-hoc comparisons were performed comparing R-EMD $D_{E-M}$ to R-EMD ${ }_{M-F}$ for each intensity $(10,20,30,40,50,60$, $70,80,90$, and $100 \%$ MVIC) (Figure 4). R-EMD $D_{E-F}$ was not compared to $\mathrm{R}-\mathrm{EMD}_{\mathrm{E}-\mathrm{M}}$ and $\mathrm{R}-\mathrm{EMD}_{\mathrm{M}-\mathrm{F}}$ because it is the sum of the two variables and, therefore, is always greater than either individual values (Keppel, 1991). These post-hoc analyses indicated that $R-E M D_{E-M}$ was significantly $\left(p<0.01\right.$ ) less than $R-E M D_{M-F}$ for all intensities $(10,20,30,40,50,60,70,80,90$, and 100\% MVIC) (Figure 4). In addition, Figure 5 shows the results of the significant one-way $(1 \times 10)$ repeated measures ANOVAs with Tukey post-hoc tests for R-EMD $D_{\mathrm{E}-\mathrm{M}} \times$ Intensity $\left(p<0.01 ; \eta_{\mathrm{p}}^{2}=0.42\right)$, R-EMD ${ }_{M-F} x$ Intensity $\left(p<0.01 ; \eta_{\mathrm{p}}^{2}=0.35\right)$, and R-EMD $D_{\mathrm{E}-\mathrm{F}} \mathrm{x}$ Intensity $\left(p<0.01 ; \eta_{p}^{2}=0.59\right)$.

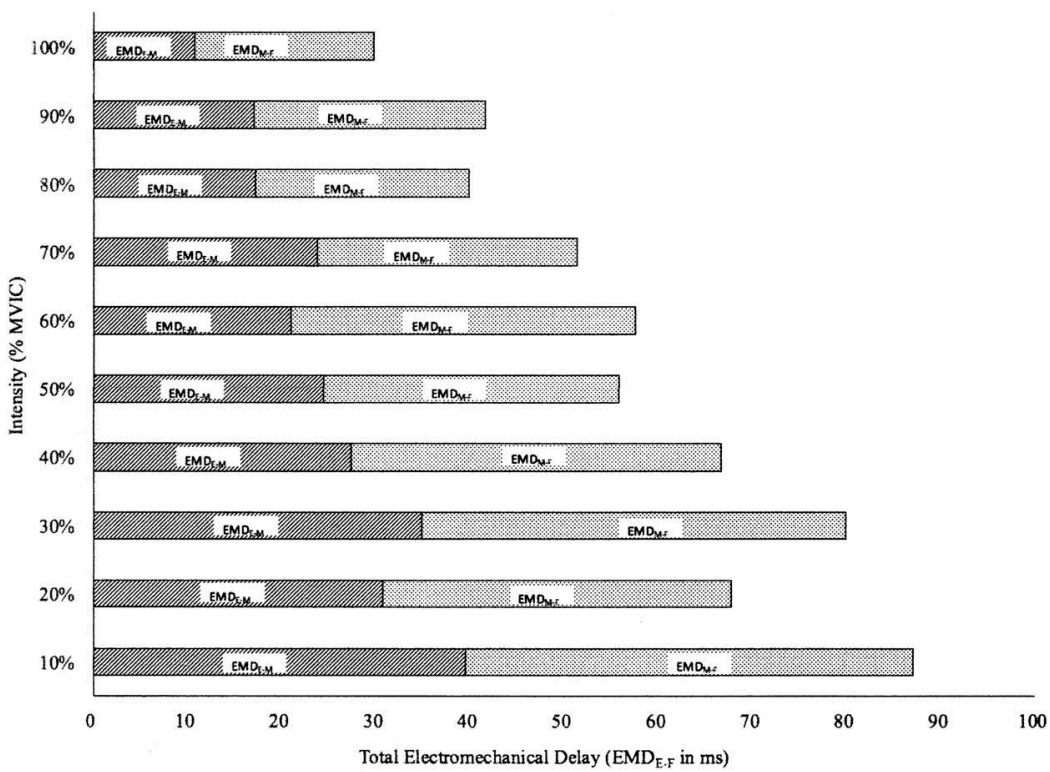

Figure 2. Total electromechanical delay (EMDE-F), collapsed across muscle, determined from the onset of the electromyographic signal to the onset of force production and the relative contributions from the onset of the electromyographic signal to the onset of the mechanomyographic signal (EMDE-M) and the onset of the mechanomyographic signal to the onset of force production (EMDM-F). 


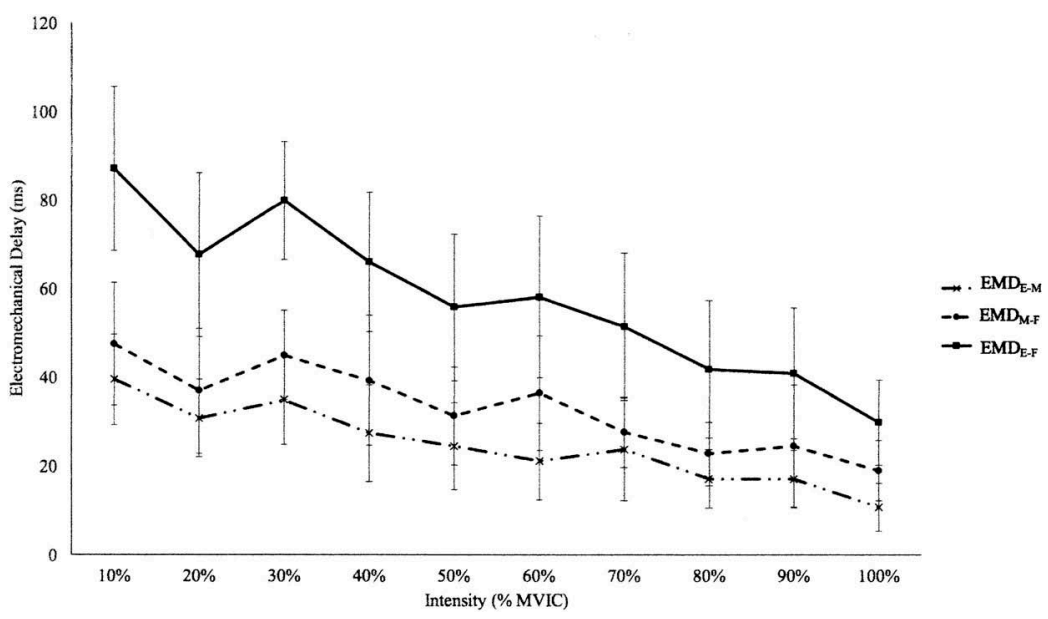

Figure 3. Electromechanical delay measurements (mean SD), collapsed across muscle, for each intensity (percentage of maximal voluntary isometric contraction $[M V I C])$. The EMDE-F represents the onset of the electromyographic signal to the onset of force production. The EMDE-M reflects the onset of the electromyographic signal to the onset of the mechanomyographic signal, and EMDM-F reflects the onset of the mechanomyographic signal to the onset of force production. Below are the results of the one-way $(1 \times 10)$ repeated measure ANOVA for EMDE-F, EMDE-M, and EMDM-F $x$ intensity.

EMDE-F x Intensity:10\% > 20, 40, 50, $6070,80,90$, and 100\%20\% > 50, 70, 80, 90, and $100 \% 30 \%>20,40,50,60,70,80,90$, and $100 \% 40 \%>50,60,70,80,90$, and $100 \% 50 \%>80,90$, and $100 \% 60 \%>80,90$, and $100 \% 70 \%>80,90$, and $100 \% 80 \%>100 \% 90 \%>100 \%$ EMDE-M x Intensity: $10 \%>20,40,50,60,70,80,90$, and $100 \% 20 \%>50,60,70,80,90$, and $100 \% 30 \%>40$, $50,60,70,80,90$, and $100 \% 40 \%>60,70,80,90$, and $100 \% 50 \%>60,80,90$, and $100 \% 60 \%>80$ and $90 \% 70 \%>80,90$, and $100 \% 80 \%>100 \% 90 \%>100 \%$ EMDM-F x Intensity: $10 \%>20$ $40,50,60,70,80,90$, and $100 \% 20 \%>70,80,90$, and $100 \% 30 \%>20,50,60,70,80,90$, and $100 \% 40 \%>50,70,80,90$, and $100 \% 50 \%>80,90$, and $100 \% 60 \%>70,80,90$, and $100 \% 70 \%$ $>80$ and $100 \% 80 \%>100 \% 90 \%>100 \%$

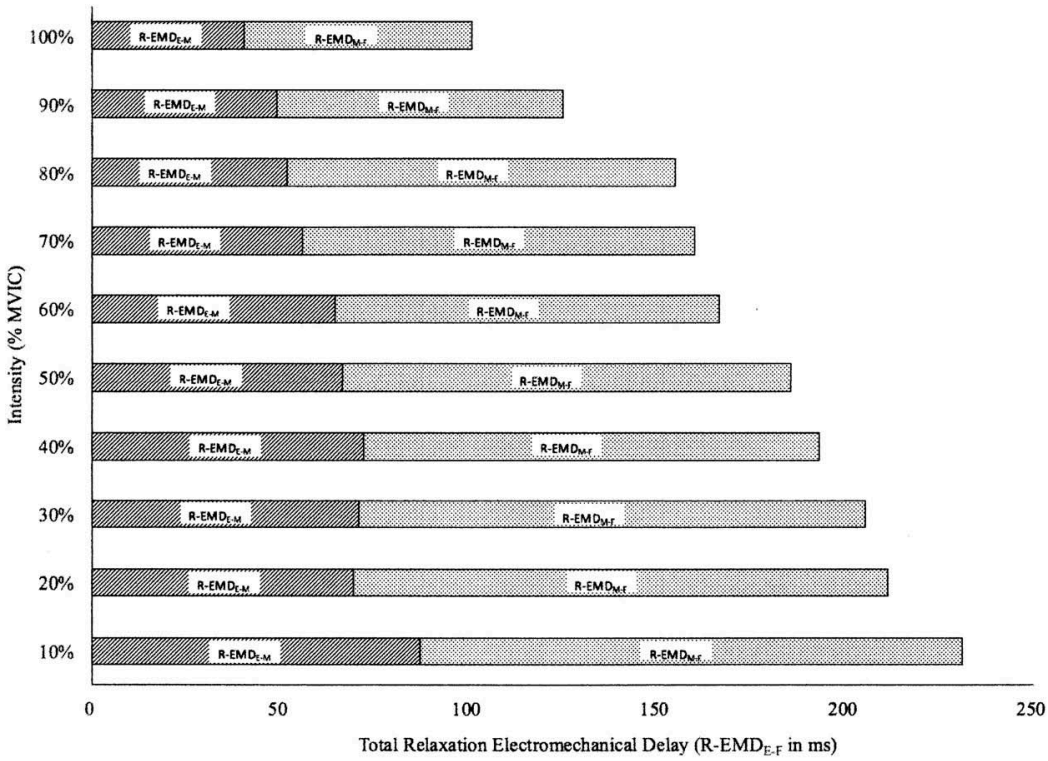

Figure 4. Total relaxation electromechanical delay (R-EMDE-F), collapsed across muscle, determined from the cessation of the electromyographic signal to the cessation of force production and the relative contributions from the cessation of the electromyographic signal to the cessation of the mechanomyographic signal (R-EMDE-M) and the cessation of the mechanomyographic signal to the cessation of force production (R-EMDM-F).

\section{Discussion}

\section{Muscle-specific differences in electromechanical delay}

In the current study, there were no significant differences between the $\mathrm{VL}, \mathrm{VM}$, and $\mathrm{RF}$ for the voluntary $E M D_{\mathrm{E}-\mathrm{M}}$, $E M D_{M-F}$, or $E M D_{E-F}$ at any intensity (10 to $100 \% \mathrm{MVIC}$ ) (Figure 2). These findings were similar to those of Zhou, Carey, Snow, Lawson, and Morrison (1998) who reported no differences in voluntary $E M D_{E-F}$ measures from the $V L$ (32.1 ms) and RF (34.7 ms) during an MVIC. In addition, the findings of the current study were in agreement with those of Chan, Lee, Wong, Wong, and Yeung (2001) who reported no differences in voluntary $\mathrm{EMD}_{\mathrm{E}-\mathrm{F}}$ measures between the $\mathrm{VL}$ (32.1 to $52.2 \mathrm{~ms}$ ) and $\mathrm{VM}$ (31.7 to $48.1 \mathrm{~ms}$ ) at various joint angles $\left(90,150\right.$, and $175^{\circ}$ of leg flexion) during MVIC muscle actions. Vos, Harlaar, and van Ingen (1991) also reported similar voluntary $E M D_{E-F}$ measurements (ranging from 95 to $110 \mathrm{~ms}$ ) from the VL, VM, and RF during 50 and $70 \%$ MVIC muscle actions. The current and previous studies (Chan et al., 2001; Vos et al., 1991; Zhou et al., 1998) indicated no differences between the $\mathrm{VL}, \mathrm{VM}$, and $\mathrm{RF}$ for $E M D_{\mathrm{E}-\mathrm{M}}, E M D_{\mathrm{M}-\mathrm{F}}$, or $E M D_{\mathrm{E}-\mathrm{F}}$ during isometric muscle actions at various intensities and joint angles. 


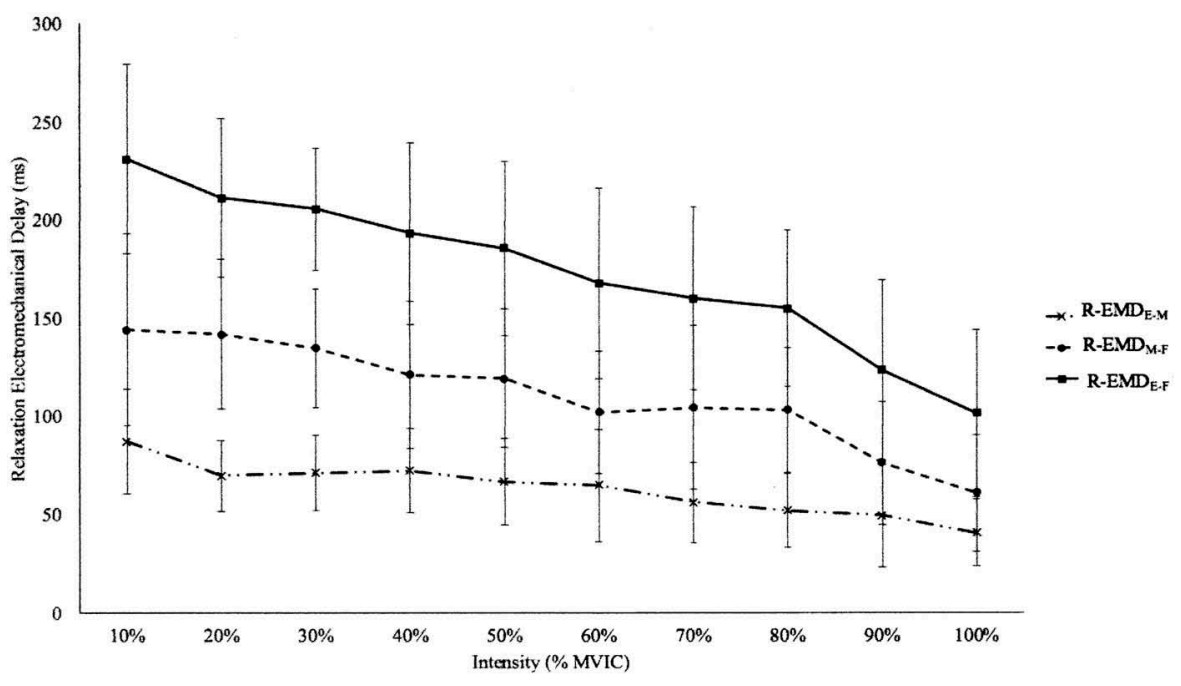

Figure 5. Relaxation electromechanical delay (R-EMD) measurements (mean SD), collapsed across muscle, for each intensity (percentage of maximal voluntary isometric contraction [MVIC]). The R-EMDE-F represents the onset of the electromyographic signal to the onset of force production. The R-EMDE-M reflects the onset of the electromyographic signal to the onset of the mechanomyographic signal, and R-EMDM-F reflects the onset of the mechanomyographic signal to the onset of force production. Below are the results of the one-way $(1 \times 10)$ repeated measure ANOVA for R-EMDE-F, R-EMDE-M, and R-EMDM-F $x$ intensity.

R-EMDE-F x Intensity: $10 \%>20,30,40,50,6070,80,90$, and $100 \% 20 \%>70,80,90$, and $100 \% 30 \%>70,80,90$, and $100 \% 40 \%>70,80,90$, and $100 \% 50 \%>70,80,90$, and $100 \% 60 \%>$ 80,90 , and $100 \% 70 \%>100 \% 80 \%>100 \%$ R-EMDE-M x Intensity: $10 \%>40,50,60,70,80,90$, and $100 \% 20 \%>40,60,70,80,90$, and $100 \% 30 \%>60,70,80,90$, and $100 \% 40 \%>60,80,90$, and $100 \% 50 \%>80,90$, and $100 \% 60 \%>90$ and $100 \% 70 \%>90$ and $100 \% 80 \%>90$ and $100 \% 90 \%>100 \%$ R-EMDM-F x Intensity:10\% > 20, 30, 40, 50, 60, 70, 80, 90, and 100\%20\% > 50, $60,70,80,90$, and $100 \% 30 \%>50,60,70,80,90$, and $100 \% 40 \%>60,70,80,90$, and $100 \% 50 \%>70,80,90$, and $100 \% 60 \%>90$ and $100 \% 70 \%>90$ and $100 \% 80 \%>90$ and $100 \% 90 \%>$ $100 \%$

\section{Intensity-specific differences in electromechanical delay}

The findings of the current study indicated a decrease in $E M D_{E-M}, E M D_{M-F}$, and $E M D_{E-F}$ with an increase in intensity for all muscles (VL, VM, and RF) (Figure 3). These findings were in agreement with those of Zhou, Lawson, Morrison, and Fairweather (1995) who reported decreases in $\mathrm{EMD}_{\mathrm{E}-\mathrm{F}}$ with an increase in intensity $(30,60$, and $80 \% \mathrm{MVIC}$ ) from the VL and RF during voluntary isometric muscle actions. In addition, Vos et al. (1991) reported a decrease in $E M D_{E-F}$ with an increase in intensity (50 to 70\% MVIC) from the VL, VM, and RF during dynamic and isometric muscle actions. Yavuz, Şendemir-Ürkmez, and Türker (2010) also reported a general decrease in $E M D_{E-F}$ with an increase in intensity (10 to $50 \%$ MVIC) from the gastrocnemius during isometric muscle actions. Thus, the current study and previous studies (Vos et al., 1991; Yavuz et al., 2010; Zhou et al., 1998) indicated an inverse relationship between intensity and the time durations for $E M D_{E-M}, E M D_{M-F}$, and $E M D_{E-F}$.

The decrease in $E M D_{E-M}$ with an increase in intensity may be explained by the potential recruitment of higher-threshold motor units. It has been suggested (Barclay, Woledge, \& Curtin, 2007; Baylor \& Hollingworth, 2012) that the recruitment of higher-threshold motor units may result in shorter time duration for excitation-contraction coupling $\left(\mathrm{EMD}_{\mathrm{E}-\mathrm{M}}\right)$ due to greater calcium $\left(\mathrm{Ca}^{2+}\right)$ release from the sarcoplasmic reticulum compared to lower-threshold motor units. For example, Baylor and Hollingworth (2012) showed that high-threshold motor units release $\mathrm{Ca}^{2+}$ at a quicker rate and greater quantities than lower-threshold, thus, resulting in faster motor unit action potentials (Baylor \& Hollingworth, 2012) and increased turnover rates (Barclay et al., 2007) which decreased the time duration for excitation-contraction coupling $\left(E M D_{E-M}\right)$. In addition, $\mathrm{EMD}_{\mathrm{M}-\mathrm{F}}$ decreased with an increase in intensity which may probably due to the recruitment of higher-threshold motor units on the series elastic component (Barclay et al., 2007; Baylor \& Hollingworth, 2012). It has been suggested (Yavuz et al., 2010) that the series elastic component $\left(E D_{M-}\right.$ F) behaves like a spring and that increases in intensity results in a stronger "pull" on the slack of the muscle-tendon unit. The recruitment of higher-threshold motors units results in a quicker and stronger "pull" of the muscle-tendon unit, decreasing the time duration of the series elastic component. Thus, the decreases in time durations for excitation-contraction coupling $\left(E M D_{E-M}\right)$ and series elastic component $\left(E M D_{M-F}\right)$ with increases in intensity are likely associated with the potential recruitment of higher-threshold motor units as well as the spring like characteristics of the series elastic component.

Electromechanical Delay: Relative Contributions from the Series Elastic Component and Excitation-Contraction Coupling

At all intensities (10 to 100\% MVIC) for all muscles (VL, VM, and $R F), E M D_{M-F}$ contributed more than $E M D_{E-M}$ to $E M D_{E-F}$ (Figures 2 and 3). In addition, as intensity increased, $E M D_{E-M}$, $E M D_{M-F}$, and $E M D_{E-F}$ decreased, but maintained similar relative contributions from $E M D_{E-M}$ and $E M D_{M-F}$ to $E M D_{E-F}$ (Figure 2). These findings were in agreement with Emiliano Cè et al. (2013) who reported greater contributions from $E M D_{M-F}$ than $E M D_{E-M}$ to $E M D_{E-F}$ from the biceps brachii during $M V I C$ muscle actions. Rampichini et al. (2014), Fabio Esposito, Limonta, and Cè (2011), and Andrade, Skiba, Krueger, Rodacki, and Parana (2016) also reported greater contributions from $E M D_{M-F}$ than $E M D_{E-M}$ to $E M D_{E-F}$ from the gastrocnemius medialis during stimulated maximal and submaximal muscle actions. Thus, the current and previous studies (Andrade et al., 2016; Cè et al., 2013; Esposito et al., 2011; Rampichini et al., 2014) indicated that at maximal and submaximal intensities, the majority of $E M D_{E-F}$ could be explained by the series elastic 
component $\left(E M D_{M-F}\right)$ and not excitation-contraction coupling $\left(E M D_{E-M}\right)$. Furthermore, the relative percentages of $E M D_{E-M}$ and $E M D_{M-F}$ to $E M D_{E-F}$ remained similar at each intensity which suggested that in non-fatigued, voluntary isometric muscle actions the factors affecting excitation-contraction coupling may also affect the series elastic component. That is, the recruitment of higher-threshold motor units associated with higher intensity isometric muscle actions affect excitation-contraction coupling $\left(\mathrm{EMD}_{\mathrm{E}-\mathrm{M}}\right)$ and the series elastic component $\left(E M D_{M-F}\right)$ equally. Thus, the current findings are aligned with the hypothesis (Barclay et al., 2007; Baylor \& Hollingworth, 2012) that the high rate and large quantities of $\mathrm{Ca}^{2+}$ released from the recruitment of higher-threshold motor units shortens $\mathrm{EMD}_{\mathrm{E}-\mathrm{M}}$ which is directly linked to a stronger and faster "pull" on the muscle-tendon unit, reducing $E M D_{M-F}$.

\section{Muscle-specific differences in relaxation electromechanical delay}

In the current study, there were no significant differences between the $V L, V M$, and $R F$ for the voluntary $R-E M D_{E-M}$, $R-E M D_{M-F}$, or R-EMD $D_{E-F}$ at any intensity (10 to $100 \%$ MVIC) (Figure 4). These findings were similar to those of FerrisHood et al. (1995) who reported no muscle-specific differences in $R-E M D_{E-F}$ from the $V L, V M$, or $R F$ during isokinetic leg extension muscle actions at 10,60 , or $120^{\circ} \mathrm{s}^{-1}$. These findings were also in agreement with Vos et al. (1991) who reported no significant differences in R-EMD $D_{E-F}$ from the $V L, V M$, and $R F$ during 50 and $70 \% \mathrm{MVIC}$ isokinetic muscle actions at 90 and $130^{\circ} \mathrm{s}^{-1}$. Like the EMD measures, the findings of the current and previous studies (Ferris-Hood et al., 1995; Vos et al., 1991) suggested that muscles within the same muscle-group share similar R-EMD measures. It is possible that the muscles within a muscle-group share similar relaxation times to avoid injury which suggested that differences in the relaxation times of muscles in the same muscle-group may compromise joint stability. For example, Van Hooren and Bosch (2016) suggested that potential muscle-imbalances as well as elongated EMD and R-EMD may result in greater injury risk. Thus, the current study indicated that at all intensities, for all superficial muscles of the quadriceps (VL, VM, and RF), there were no differences in time durations for the voluntary $R-E M D_{E-M}$, R-EMD ${ }_{M-F}$, or R-EMD $D_{E-F}$.

\section{Intensity-specific differences in relaxation electromechanical delay}

The findings of the current study indicated a decrease in $R-E M D_{E-M}, R-E M D_{M-F}$, and $R-E M D_{E-F}$ with an increase in intensity for all muscles (VL, VM, and RF) (Figure 5). These findings were similar to those of Vos et al. (1991) who reported greater $\mathrm{R}-\mathrm{EMD}_{\mathrm{E}-\mathrm{F}}$ from the $\mathrm{VL}, \mathrm{VM}$, and RF at 50 compared to $70 \%$ $M V I C$ isokinetic leg extension muscle actions. These findings were similar to those during the $E M D_{E-M}, E M D_{M-F}$, and $E M D_{E-F}$ measurements which suggested that a relationship exists between EMD and R-EMD's response to intensity. That is, the time durations for both EMD and R-EMD measurements decreased with an increase in intensity. Specifically, as intensity increases there is a decrease in R-EMD because of the recruitment of higher-threshold motor units allowing for greater cycling rates of $\mathrm{Ca}^{2+}$ which may allow for faster relaxation times. For example, Viistalo and Komi (1981) suggested that relaxation delays reflect the rate of $\mathrm{Ca}^{2+}$ removal from actomyosin crossbridges by the sarcoplasmic reticulum. The greater turnover rate of $\mathrm{Ca}^{2+}$ in recruitment of higher-threshold motor units compared to lower-threshold motor units (Barclay et al., 2007) may partially explain the decrease in R-EMD measurements with an increase in intensity. It has also been suggested (Yavuz et al., 2010) that the stronger the "pull" on the muscle-tendon unit during the initiation of the muscle action, the less compliant the series elastic component and that with less compliance there can be quicker relaxation times.

\section{Relaxation electromechanical delay: relative} contributions from the series elastic component and excitation-contraction coupling

At all intensities (10 to $100 \% \mathrm{MVIC}$ ) for all muscles (VL, VM, and $R F), R-E M D_{M-F}$ contributed more than R-EMD $D_{E-M}$ to $R-E M D_{E-F}$ (Figures 4 and 5). In addition, as intensity increased, R-EMD $D_{E-M}$, $\mathrm{R}-\mathrm{EMD}_{\mathrm{M}-\mathrm{F}}$, and $\mathrm{R}-\mathrm{EMD}_{\mathrm{E}-\mathrm{F}}$ decreased, but maintained similar relative contributions from R-EMD $D_{E-M}$ and $R-E M D_{M-F}$ to $R-E M D_{E-F}$ (Figure 4). These findings are in agreement with those of Emiliano Cè et al. (2015) who reported greater relative contributions from the series elastic component $\left(\mathrm{R}-\mathrm{EMD}_{\mathrm{M}-\mathrm{F}}\right)$ than excitation-contraction coupling $\left(\mathrm{R}-E M D_{\mathrm{E}-\mathrm{M}}\right)$ to $\mathrm{R}-E M D_{\mathrm{E}-\mathrm{F}}$ from the biceps brachii during MVIC forearm flexion muscle actions. Thus, the current and previous studies (Cè et al., 2014, 2015; Esposito, 2013; Ferris-Hood et al., 1995) indicated that during non-fatigued conditions, the reversal of the series events associated with excitation-contraction coupling are shorter in duration than the time duration to return the series elastic component to a resting state at all intensities. Similar to $E M D_{E-M}$ and $E M D_{M-F}$, the mechanisms associated with $R-E M D_{E-M}$ and $R-E M D_{M-F}$ are closely related and also decreased similarly with an increase in intensity. It is likely that that an increase in intensity results in the recruitment of higher-threshold motor units which result in shorter time duration for the reversal of excitation-contraction coupling $\left(R-E M D_{E-M}\right)$. Similarly, these findings further supported the hypothesis that an increase in intensity results in a decrease in the compliance of the series elastic component $\left(R-E M D_{M-F}\right)$.

\section{Summary}

In the current study, there were no differences between the $\mathrm{VL}$, VM, and RF for all EMD or R-EMD measurements which suggested that each muscle in a muscle-group may have similar EMD measurements. The current findings also indicated an inverse relationship between intensity and EMD and R-EMD measurements. That is, with an increase in intensity, EMD (EMD $D_{E-M}, E M D_{M-F}$ and $\left.E M D_{E-F}\right)$ and R-EMD (R-EMD $D_{E-M}$, $R-E M D_{M-F}$, and $R-E M D_{E-F}$ ) measurements will decrease. The decreases in time durations for initiation $\left(E M D_{E-M}\right)$ and relaxation $\left(R-E M D_{E-M}\right)$ of excitation-contraction coupling and series elastic component $\left(E M D_{M-F}\right)$ with increases in intensity were likely associated with the recruitment of higher-threshold motor units as well as the spring like characteristics of the 
series elastic component. In addition, during both EMD and R-EMD measurements for all intensities there were similar relative contributions from $E M D_{E-M}$ and $E M D_{M-F}$ to $E M D_{E-F}$ as well as R-EMD $D_{E-M}$ and R-EMD ${ }_{M-F}$ to R-EMD $D_{E-F}$ (Figures 3 and 5). Thus, the time duration for excitation-contraction coupling $\left(E M D_{E-M}\right)$ and the reversal of the processes associated with excitation-contraction coupling $\left(R-E M D_{E-M}\right)$ were less than the series elastic component $\left(\mathrm{EMD}_{\mathrm{E}-\mathrm{M}}\right)$ and relaxation of the series elastic component (R-EMD $\left.{ }_{M-F}\right)$.

\section{Disclosure statement}

No potential conflict of interest was reported by the authors.

\section{References}

Abe, T., Kumagai, K., \& Brechue, W. (2000). Fascicle length of leg muscles is greater in sprinters than distance runners. Medicine and Science in Sports and Exercise, 32(6), 1125-1129. doi:10.1097/00005768-200006000-00014

Andrade, S., Skiba, G., Krueger, E., Rodacki, A., \& Parana, C. (2016). Electromechanical delay from mechanomyography in long-term strength trained men. Journal Exercise Physiological Online, 19(3), 110-119.

Barclay, C., Woledge, R., \& Curtin, N. (2007). Energy turnover for Ca2+ cycling in skeletal muscle. Journal of Muscle Research and Cell Motility, 28(4-5), 259-274. doi:10.1007/s10974-007-9116-7

Basmajian, J., \& De Luca, C. (1985). Muscles alive. Muscles Alive: Their Functions Revealed by Electromyography, 278, 126.

Baylor, S., \& Hollingworth, S. (2012). Intracellular calcium movements during excitation-contraction coupling in mammalian slow-twitch and fast-twitch muscle fibers. The Journal of General Physiology, 139 (4), 261-272. doi:10.1085/jgp.201210773

Begovic, H., Zhou, G., Li, T., Wang, Y., \& Zheng, Y. (2014). Detection of the electromechanical delay and its components during voluntary isometric contraction of the quadriceps femoris muscle. Frontiers in Physiology, 5. doi:10.3389/fphys.2014.00494

Cè, E., Rampichini, S., Agnello, L., Limonta, E., Veicsteinas, A., \& Esposito, F. (2013). Effects of temperature and fatigue on the electromechanical delay components. Muscle \& Nerve, 47(4), 566-576. doi:10.1002/mus.v47.4

Cè, E., Rampichini, S., \& Esposito, F. (2015). Novel insights into skeletal muscle function by mechanomyography: From the laboratory to the field. Sport Sciences for Health, 11(1), 1-28. doi:10.1007/s11332-0150219-z

Cè, E., Rampichini, S., Limonta, E., \& Esposito, F. (2014). Fatigue effects on the electromechanical delay components during the relaxation phase after isometric contraction. Acta Physiological, 211(1), 82-96. doi:10.1111/apha.2014.211.issue-1

Cè, E., Rampichini, S., Venturelli, M., Limonta, E., Veicsteinas, A., \& Esposito, F. (2015). Electromechanical delay components during relaxation after voluntary contraction: Reliability and effects of fatigue. Muscle \& Nerve, 51(6), 907-915. doi:10.1002/mus.v51.6

Chan, A. Y., Lee, F., Wong, P., Wong, C., \& Yeung, S. (2001). Effects of knee joint angles and fatigue on the neuromuscular control of vastus medialis oblique and vastus lateralis muscle in humans. European Journal of Applied Physiology, 84(1-2), 36-41. doi:10.1007/s004210000326

Costa, P., Ryan, E., Herda, T., Walter, A., Hoge, K., \& Cramer, J. (2012). Acute effects of passive stretching on the electromechanical delay and evoked twitch properties: A gender comparison. Journal of Applied Biomechanics, 28(6), 645-654. doi:10.1123/jab.28.6.645
Esposito, F. (2013). Reliability of the electromechanical delay components assessment during the relaxation phase. Physiology Journal, 25(3), 1-7.

Esposito, F., Limonta, E., \& Cè, E. (2011). Passive stretching effects on electromechanical delay and time course of recovery in human skeletal muscle: New insights from an electromyographic and mechanomyographic combined approach. Euro Journal Applications Physiological, 111(3), 485-495. doi:10.1007/s00421-010-1659-4

Esposito, F., Orizio, C., \& Veicsteinas, A. (1998). Electromyogram and mechanomyogram changes in fresh and fatigued muscle during sustained contraction in men. European Journal of Applied Physiology, 78(6), 494-501. doi:10.1007/s004210050451

Ferris-Hood, K., Threlkeld, A., Horn, T., \& Shapiro, R. (1995). Relaxation electromechanical delay of the quadriceps during selected movement velocities. Electromyography and Clinical Neurophysiology, 36(3), 157-170.

Hermens, H., Freriks, B., Merletti, R., Stegeman, D., Blok, J., Rau, G., ... Hägg, G. (1999). European recommendations for surface electromyography. Roessingh Research and Development, 8(2), 13-54.

Keppel, G. (1991). Design and analysis: A researcher's handbook. Upper Saddle River, NJ: Prentice-Hall.

Kulig, K., Andrews, J. G., \& Hay, J. G. (1984). Human strength curves. Exercise and Sport Sciences Reviews, 12(1), 417-466. doi:10.1249/00003677-19840100000014

Norman, R., \& Komi, P. (1979). Electromechanical delay in skeletal muscle under normal movement conditions. Acta Physiologica Scandinavica, 106(3), 241-248. doi:10.1111/j.1748-1716.1979.tb06394.x

Orizio, C., Esposito, F., Paganotti, I., Marino, L., Rossi, B., \& Veicsteinas, A. (1997). Electrically-elicited surface mechanomyogram in myotonic dystrophy. Italian Journal Neurologic Sciences, 18(4), 185-190. doi:10.1007/ bf02080462

Rampichini, S., Cè, E., Limonta, E., \& Esposito, F. (2014). Effects of fatigue on the electromechanical delay components in gastrocnemius medialis muscle. European Journal of Applied Physiology, 114(3), 639-651. doi:10.1007/s00421-013-2790-9

Smith, C., Housh, T., Herda, T., Zuniga, J., Camic, C., Bergstrom, H., .. Johnson, G. (2016). Electromyographic responses from the vastus medialis during isometric muscle actions. International Journal of Sports Medicine, 37(8), 647-652. doi:10.1055/s-0035-1564174

Stock, M., Olinghouse, K., Mota, J., Drusch, A., \& Thompson, B. (2015). Muscle group specific changes in the electromechanical delay following short-term resistance training. Journal Sciences and Medica Sport, 19 (9), 761-765. doi:10.1016/j.jsams.2015.11.002

Van Hooren, B., \& Bosch, F. (2016). Influence of muscle slack on highintensity sport performance: A review. Strength \& Conditioning Journal, 38(5), 75-87. doi:10.1519/SSC.0000000000000251

Viistalo, J., \& Komi, P. (1981). Interrelationships between electromyographic, mechanical, muscle structure and reflex time measurements in man. Acta Physiologica Scandinavica, 111(1), 97-103. doi:10.1111/j.1748-1716.1981. tb06710.x

Vos, E., Harlaar, J., \& van Ingen, S. G. (1991). Electromechanical delay during knee extensor contractions. Medica Sciences Sport Exercise, 23 (10), 1187-1193. doi:10.1249/00005768-199110000-00013

Yavuz, Ş., Şendemir-Ürkmez, A., \& Türker, K. (2010). Effect of gender, age, fatigue and contraction level on electromechanical delay. Clinical Neurophysiology, 121(10), 1700-1706. doi:10.1016/j.clinph.2009.10.039

Zhou, S., Carey, M., Snow, R., Lawson, D., \& Morrison, W. (1998). Effects of muscle fatigue and temperature on electromechanical delay. Electromyography and Clinical Neurophysiology, 38(2), 67.

Zhou, S., Lawson, D., Morrison, W., \& Fairweather, I. (1995). Electromechanical delay in isometric muscle contractions evoked by voluntary, reflex and electrical stimulation. European Journal of Applied Physiology and Occupational Physiology, 70(2), 138-145. doi:10.1007/BF00361541 